\title{
Migration as adaptation? Exploring the scope for coordinating environmental and migration policies in the European Union
}

\author{
Andrew Geddes \\ Department of Politics, University of Sheffield, Elmfield, Northumberland Road, \\ Sheffield S10 2TU, England; e-mail: andrew.geddes@eui.eu \\ Andrew Jordan \\ School of Environmental Sciences, University of East Anglia, Norwich Research Park, \\ Norwich NR4 7TJ, England; e-mail: a.jordan@uea.ac.uk \\ Received 13 January 2012; in revised form 3 July 2012
}

\begin{abstract}
We explore the links between environmental change, human migration, and adaptation in the relatively mature governance system of the European Union (EU). It is shown that these connections are limited and, when made, tend to be security focused. This situation inhibits scope for migration (both internally within states and internationally between states) to be understood as a form of adaptation to economic, social, political, demographic, and environmental change. We assess the underlying dynamics of EU environmental policy, note the main modes and instruments used, and identify some of the chief dynamics in this policy field. Finally, conclusions are drawn with respect to how, in future, the EU might interact with nonmember states on environment and migration-related issues.
\end{abstract}

Keywords: migration, environmental change, European Union, adaptation, development, security

\section{Introduction}

This paper has as its primary focus EU environmental governance modes and policies, specifically their interaction-both potential as well as real—with migration governance modes and policies. Close attention is paid to underlying conceptualisations of environmental and migration policy issues, as well as to the specific modes of governance that have developed at EU level to coordinate better between them. We assess the extant situation and also the adaptive capacity of EU governance systems in relation to the future challenges posed by environmental change and migration. Adaptive capacity is taken to refer to decision-making processes, sets of actions, and associated capacities to deal with future changes to systems (Nelson et al, 2007, page 397). This paper suggests a reconceptualisation of these challenges focused on links between migration, development, and adaptation, and thus questions current narrowly focused and security-driven approaches that may well be counterproductive in the longer term.

We proceed from some basic understandings of the underlying relationships between environmental change, migration, and governance that inform the questions posed in the paper. First, environmental and climate change can directly drive migration, but their effects are more likely to be evident through interactions with other economic, social, political, and demographic drivers (Black et al, 2011). Environmental and climatic change can, in turn, also affect the ways in which these other economic, social, political, and demographic drivers operate, through, for instance, effects on the sustainability of human livelihoods. Thus, and in common with the argument developed in this theme issue's introductory 
paper (Geddes et al, 2012), migration is understood as a multicausal phenomenon with environmental change as one potential cause or driver of movement either within or between states. Second, migration, whether within or between states, is understood as a form of adaptation at household level in response to threats to the sustainability of livelihoods. Migration is thus a temporal and spatial readjustment to inequalities both within and between states (Black et al, 2011). The key point here is the assumption that migration is a form of adaptation, not a failure to adapt. As will be shown, this has important implications for policy and governance in terms of potential linkages between migration, development, and adaptation policies, even in a relatively mature policy system such as the EU, which already has well-developed policies on the environment and on migration. Third, we explore the implications of the argument developed in the introductory paper-namely, that environmental change and migration should not be understood as ex post challenges to governance but, rather, as constituted by governance. By this, Geddes et al (2012) mean that the constitution of governance systems and the inequalities embedded within them, at both domestic and international levels, play a key and powerful role in shaping environmental change and migration as social and political issues within states and between states.

These understandings generate three questions. First, to what extent have linkages between migration and environmental change been evident in existing policy responses at EU level? Second, is there evidence within the EU's responses that migration is viewed as a form of adaptation or as a failure to adapt? Third, to what extent can new modes of governance in the EU provide novel ways of responding to the links between environmental change and migration? To address these questions, we begin by exploring the links between environmental change, migration, and adaptation. We then assess the underlying scope and dynamics of EU environmental policy, note the main modes and instruments used, and identify some of the chief dynamics in this policy field. In this section we also specify the limited attention to linkages between environmental change and migration within this policy field. We also pay close attention to the types of coordinating mechanisms that could in theory be used to ensure that EU-level policies developed in the area of migration take account of those in the area of environment, and vice versa. The extent to which these various mechanisms have been used in the past by the EU (and its member states) to coordinate policy interventions within and across these two areas is then analysed, and conclusions are derived with respect to future policy and governance.

\section{Environmental change, migration, and adaptation}

The debate about linkages between migration and environmental change has been dominated by arguments about potential large-scale movement as a result of environmental change (for example, Myers, 1997; 2001). It has been claimed that such changes caused by, for example, rising sea levels, could displace potentially hundreds of millions of people. Recent research has questioned some of the underlying assumptions informing these assessments (for example, Foresight, 2011), while the potentially damaging effects in terms of the 'securitisation' of migration arising from this focus on very large numbers of potential migrants have also been highlighted (White, 2011). In particular, an underlying assumption seems to be that many of them will head to relatively rich and developed countries such as those in the EU.

As noted in the introduction to this theme issue (Geddes et al, 2012), the effects of environmental change on migration are most likely to be made evident through interaction with other drivers or causes of migration, such as economic change, political conflict, the social connections between migrants and their places of origin, and demographic change. The complex and multicausal nature of migration means that it is very difficult to delineate a group of people who might be termed 'environmental migrants' or 'climate refugees'. The mediating effects of other drivers hold for migration both within states (internal migration) 
or between states (international migration). It has also been argued that the policy challenge is not necessarily that of delineating and addressing 'environmental trigger' but comprises a more complex threefold set of challenges associated with: (i) those who move either internally or internationally as a result of environmental change; (ii) those who move towards not away from environmental risk, particularly as a result of movement towards large urban areas for essentially economic reasons; and (iii) those who lack the resources to move and may find themselves potentially 'trapped' in places that expose them to serious environmental hazards. Much of this international and intranational migration is likely to occur outside of the EU and, in particular, raise important questions about urban development and governance in rapidly growing cities in parts of Asia and Africa, which are more likely to form part of the EU's extensive human development agenda (CEC, 2011a).

In his analysis of climate change and migration White (2011) shows that the EU has tended to focus on restricting migration, while countries such as Morocco that have been seen as potential transit countries for migrants seeking to access EU member states have used arguments about the effects on migration of environmental change to claim resources from the EU to develop controls to prevent movement across and out of their territory. Thus, EU member states will experience the effects of climate change, but it is important to note when assessing the constitution of policy and governance in this complex issue area that many of the key effects of environmental change on migration may well occur outside the EU, be embedded within the constitutive features of governance systems more broadly, and also raise questions about linkages between migration, development, and adaptation that have an extra-EU dimension. EU migration policy has acquired a significant external dimension both through a focus on the 'export' of border controls and also in the creation of linkages between migration and development. All have become important components of what the EU now refers to as its Global Approach to Migration and Mobility (GAMM) (CEC, 2011b; Geddes, 2005; 2008; Lavenex, 2006). The GAMM made only passing reference to the links between climate change and migration when noting that the EU's five-year plan on the development of internal security - the so-called Stockholm Programme - had called for a communication from the Commission on links between climate and migration (see Geddes and Somerville, 2012).

The debate about environmental change and migration also raises another key issue. The 'environmental trigger' argument focuses on the scope for mass displacement as, for example, rising sea levels affect potentially hundreds of millions of people. But this view tends to see migration as an emergency response to direct threats to life and livelihoodsthat is, people move as a last resort. There has, however, been increased interest in the ways in which migration both within and between states can be a form of adaptation that sustains livelihoods for the people who move, but also for those that receive additional resources, such as remittance income, as a result of migration. For example, McLeman and Smit (2006) use concepts of vulnerability, risk, and adaptive capacity to show the ways in which migration in rural Oklahoma as a result of crop failures resulting from drought and flooding can be understood as a form of adaptation to climate change. They note that:

"[m] igration should not be considered as a simple or automatic response to a singular risk, climate related or otherwise. Many factors combine to influence human spatial behaviour, and migration sensitivities and options vary greatly among regions and social groups" (page 32).

This point about migration as a form of adaptation has been taken forward and explored in other settings (see Foresight, 2011), but existing modes of environmental governance and policy at EU level have not been organised in this way. In fact, where migration has been assessed (and in general it has not), the link most often made is to security. There has, however, been growing interest within the EU in what are sometimes referred to as 'root 
causes' approaches to migration policy that seek to deal with the core economic, social, and political drivers of migration through, for example, establishing links between migration and development policies. However, as noted, little attention has been paid within the EU to links between migration and environmental change and especially those that consider migration as a form of adaptation to environmental change. Security-driven responses tend to see migration as a failure of adaptation with policy focused on 'keeping people in their place' (Bakewell, 2008). Policy responses that focus on migration as a form of adaptation would tend to see migration as a potential solution in the face of threats to household livelihoods. Migration can then generate the transfer of flows such as remittance income between migrants and family members in places of origin. 'Migration as adaptation' would require governance and policy responses capable of making connections between environmental change, migration, adaptation, and development. This is a significant challenge to the EU governance system because of the powerful domestic drivers of migration policy and its high domestic political salience in member states.

\section{EU environment policy - what kind of policy area is it?}

At its founding in 1957 the EU had no environmental policy. In fact, the word 'environment' was not even mentioned in the Treaty of Rome. In the 1960s and 1970s the output of legislation was relatively slow, but then it rocketed in the 1980s and 1990s, tailing off again in the 2000s. Nowadays, the environment is a relatively mature area of EU activity, which is "broad in scope, extensive in detail and stringent in effect" (Weale et al, 2000, page 1). There are EU-level actors (such as the European Commission and the European Parliament), there are those that principally operate at a national level (eg, national ministries and agencies), and there are those that move between the two (environmental pressure groups and national civil servants, for example). It conforms to a set of guiding principles, follows a set of regularly updated environmental action programmes, and has an explicit basis in the founding treaties (Jordan and Adelle, 2012a). In short, it has successfully evolved from what was a set of incidental measures into a mature system of multilevel environmental governance (Jordan and Adelle, 2012b). Qualified majority voting (QMV) has been the norm since the mid-1990s, with a significant role for the European Parliament. By contrast, in the area of migration QMV began to be used for some issues only in the early 2000s in the area of migration, while it was not until the Lisbon Treaty came into effect in 2009 that migration and asylum became subject to common institutional rules and procedures such as QMV and codecision making with the European Parliament.

The fact that the Nice and Lisbon Treaties (Benson and Adelle, 2012; Benson and Jordan, 2008) were so lacking in new environmental content suggests that the big constitutional questions of this policy area (eg, which level of governance should do what?) had essentially been settled by the late 1990s. By contrast, migration policy has evolved rapidly during the 2000s. The main focus has been on border controls and the development of control capacity in newer member states in Southern, Central, and Eastern Europe, as well as the 'export' of EU migration policy priorities to nonmember states (Geddes, 2008).

EU environmental policy has the following key characteristics (Jordan and Adelle, 2012c). First, it is relatively broad in focus. It ranges from older concerns such as air and water pollution through to more modern issues such as genetic modification, access to environmental information, and biofuels. Where problems span borders or involve a strong trade dimension, the 'value added' of EU involvement seems self-evident (the EU tends to be more active in relation to the governance of traded products than production processes). But many issues now governed by the EU do not exhibit these characteristics: zoos, bathing and drinking water quality, waste water treatment, bird habitats, and renewable energy supplies, to name just a few. Crucially, there are some areas of policy where the EU's role is still 
not completely accepted - and hence the Council operates on the basis of unanimity rather than QMV. These include areas such as land-use planning, water resources, and the selection of states' energy supplies that could potentially have a significant migration dimension.

Second, EU environmental policy is mainly regulatory in nature: despite significant learning interactions between states, regulation remains the EU's instrument of choice (Jordan et al, 2005; 2011). Thus, the EU operates mainly as a 'regulatory state' in the environmental sphere (Jordan et al, 2012a; 2012b). The lack of a sound legal base in the treaty for fiscal measures has certainly played a part in retarding the use of environmental taxes, as has political resistance from certain actors. Meanwhile, voluntary agreements have been trialled but not extensively employed (Jordan et al, 2012b).

Third, EU policy has a hugely important impact on national policy and politics: a very significant proportion of national policy is now decided in or involving the EU. According to one expert on EU-UK policy interactions, it is "impossible to understand the environmental policy of any of the ... Member States without understanding [EU] policy" (Haigh, 1992, page xi) as the two are now inextricably intertwined. Europeanisation is the process through which EU-level policies affect domestic systems. In the last ten years analysts have shown that every state has been deeply affected by EU membership, even those so-called leader states that worked the hardest to shape EU policies in the first place. While some aspects of national policy have become more similar, no long-term convergence towards a common 'European' model is apparent. Multilevel environmental governance in the EU has not yet created more uniform environmental governance (Weale et al, 2000, page 468).

Fourth, EU policy is relatively popular amongst the public. In terms of its political popularity, environmental policy represents one of the EU's greatest 'success stories'. Eurobarometer polls regularly indicate relatively high levels of support for dealing with environmental issues at EU level. This provides some contrast to the situation in migration policy. While there is support amongst European publics for a common EU approach (with some variation between member states), there is a strong streak of anti-immigration sentiment in the EU. Thus, while the EU's role in environmental protection is relatively popular amongst EU citizens (Jordan and Adelle, 2012c), immigration is not. This presents some political challenges when trying to make more positive connections between migration, development, and adaptation.

\section{The underlying dynamics of EU environmental policy}

Having introduced key elements of national and EU-level policy making, it is important to understand how these interact with one another to shape EU-level policy. This is particularly relevant in the context of assessment of the adaptive capacity of EU governance systems to respond to future changes. The existing scholarship in this area (eg, Jordan, 2005; Jordan and Adelle, 2012b; Lenschow, 2005; 2012) has revealed the significance of at least three interacting dynamics: Europeanisation, internationalisation, and cross-sectoral environmental policy integration (Benson and Jordan, 2012). There are clear parallels here with the 'multilevelling' of migration policy, although connections between these two fields are extremely limited and, when made, tend to address security-related dimensions of links between environmental change and migration.

These three interacting dynamics could be thought of as proximate causes of policy changes. Underlying them are deeper causes-notably, rising public demands for higher environmental standards (ie, as manifest in the new social movement of environmentalism) and the political push for deeper European integration across many policy areas. The demands for higher environmental quality have, of course, fluctuated, but have generally cycled in an upward direction. Consequently, at any point in time there will be at least one group of actors in Brussels who are seeking to pioneer higher standards at EU level or to resist the dilution 
or dismantling of existing standards. Public support for deeper European integration has generally declined over time, although support for collaboration on environmental issues has held up better than it has in other policy areas (see below).

\section{Europeanisation}

The analysis of Europeanisation has been a major growth area in EU studies. While there has been a wide range of work exploring these effects, there is a common focus on the EU's impacts on domestic politics. These impacts can be seen broadly on both formal institutional and organisational structures, but also on more normative dimensions of domestic politics (for example, Radaelli, 2002). Emphasis has also been placed on the key role played by domestic institutions in responding to European integration. This response can take the form of adaptation, although when adaptation occurs this tends to be with 'national colours'that is, consistent with national 'ways of doing things' (Green-Cowles et al, 2002). For the purposes of the analysis that follows Europeanisation can thus be defined in two ways (Bache and Jordan, 2006). First, it addresses the development of common rules at EU level. Second, it concerns the process through which these common rules 'boomerang back' and affect national policy and politics.

Once a regulatory competition has started in a particular issue area, the outcomes can be difficult to predict. The Commission may use its right of initiative to push policy in a certain direction at the proposal stage; lobby groups become involved with their own preferences; and agreement eventually has to be secured with the European Parliament. What emerges from the long process of policy development is often a compromise - that is, something that bears some resemblance to preexisting national standards but is not precisely the same as any one national model or model of policy. Importantly, the essentially hybrid character of EU policy means that it cannot easily be absorbed into any national system without some subsequent adjustment (ie, Europeanisation) (Jordan and Liefferink, 2004). In general terms, individual aspects of national policy have been Europeanised in slightly different ways. Thus, the content of their policies (ie, broad goals, the nature of policy instruments, and the way they are calibrated) has been more deeply affected than their style (eg, anticipatory or reactive, consensual or adversarial) or administrative structures. And while some aspects of national policy have become more similar, no long-term convergence towards a common 'European' model is apparent (Jordan and Liefferink, 2004). For now, national policies and policy systems appear to be far too strongly rooted in national history to respond in precisely the same way to policy demands emerging from the EU. In other words, more multilevel environmental governance in the EU has not yet translated into more uniform environmental governance (Weale et al, 2000, page 468). This also suggests that the 'adaptation pathways' within member states will contain a strong domestic element and that attempts to build links between migration and environmental change and migration will encounter well-established national ways of doing things that will channel responses and may also lead to resistance to new understandings at the EU level.

\section{Internationalisation}

The discussion thus far may have given the impression that EU environmental policy has been mostly unaffected by external drivers. In fact, a far larger proportion of EU environmental policy derives from international-level discussions than is commonly thought. After all, it was the 1972 UN conference in Stockholm that first gave EU actors an impetus to discuss their respective national approaches, build new institutions, and, eventually, develop common policies at EU level. An internal-external dynamic has therefore been apparent since the very dawn of EU environmental policy.

What does this particular dynamic entail? First and foremost, it involves EU-level actors (chiefly, the Commission and the Presidency of the Council of Ministers) working alongside 
the member states in international-level discussions. In many issue areas the EU has sought to be an environmental leader. The reasons for this are many and varied, including the EU's desire to expand its 'soft' power into areas of international affairs that were not dominated by the US; the desire of European industries to achieve a level playing field globally; and to a general concern to shield the EU's own policies from challenge in world trade bodies (Kelemen, 2010).

From the perspective of intersectoral coordination within the EU, what is most interesting is how the various parts of the EU (the Commission, the Parliament, the European Council, the Presidency, etc) arrive at a common position in international discussions. In other words, at what point does member-state control of the EU's 'foreign environmental policy' end and common EU control begin?

In short, it varies from one issue area to the next because states have generally resisted any attempt to make the environment an area of exclusive EU competence (eg, on a par with trade policies - for example, where the Commission represents the EU in international trade talks). In turn, this has engendered highly complex and-it has to be said-rather introspective discussions about who should take the lead in a given environmental issue area and according to what decision-making procedure (Lenschow, 2012). In the 1970s and 1980s the ability of 'laggard' states to prevent the EU from developing a more progressive collective position forced it to trail behind the US in emerging global issue areas such as stratospheric ozone depletion. In the 1990s changing internal political and legal conditions allowed the EU to adopt a more progressive position in areas such as global climate change, biodiversity protection, and sustainable development (Jordan et al, 2010). However, effective international leadership outside the EU depends partly on the presence, amongst others, of stronger internal policy coordination and delivery structures within it.

This takes us to a second dimension: the drive to give the EU an international face has, in turn, boomeranged back and affected internal EU policies via a process which is rather analogous to Europeanisation. For example, the EU had to develop a suite of internal policies to control chemicals (such as chlorofluorocarbons) that deplete the ozone layer: a policy area originally formalised and transformed by two important UN agreements brokered in Vienna (1985) and Montreal (1987). In the coming years international climate change commitments entered into at Kyoto (1997) and Copenhagen (2009) will similarly affect established areas of internal EU policy making such as agriculture, transport, and energy. The rationale in this respect is to avoid a situation in which member states adopt different approaches to implementing international commitments - especially differences that could disrupt the operation of the internal market.

\section{Environmental policy integration}

Environmental policy integration (EPI) is a long-standing goal of EU policy and is widely regarded as a key condition to enable sustainable development in the longer term. In practice, it equates to an attempt to ensure that economically powerful sectors such as transport, agriculture, and energy build an environmental dimension into their policy design and implementation processes. Thus far, this approach to EPI has not extended to include migration policy actors. It is, however, instructive to understand more about EPI in the context of this paper's assessment of the adaptive capacity of the EU environmental governance system, before considering the specific issue of migration.

In the past, the Directorate-General (DG) for the Environment within the European Commission approached integration from a somewhat weaker and more defensive positionthat is, by issuing regulations to compel these sectors to take environmental issues into account. The obvious benefit of this rather segmented approach was that a large amount of ambitious legislation could be adopted relatively quickly. The drawback was that a great deal 
of it was either watered down in the Council or systematically ignored by cognate sectors at the implementation stage (Börzel, 2001; Jordan, 1999).

In the 1990s the environmental sector mapped out a transition towards a more systematically integrated approach (Jordan and Lenschow, 2008). It seemed to offer the tantalising prospect that the 'non'environmental sectors might eventually bear more of the responsibility for adopting strong and implementable environmental policies within the EU. And it created an opportunity for new links to be built between environmental policy and potentially relevant cognate sectors such as migration policy. What these efforts actually produced in practice is assessed in the following section.

To conclude, in the past analysts tried to explain EU environmental policy in terms of one particular dynamic (eg, regulatory competition) and/or in rather binary terms (leaders versus laggards; EU institutions versus member states; industry versus environmentalists). But as the sector has gradually matured and become more and more deeply entangled with other sectors, binary explanations no longer suffice (Lenschow, 2005; 2012). For example, many industries now realise that having sound environmental policies plays well with investors, customers, and their own workforce. Moreover, the nature of policy outputs and their differentiated outcomes on the ground in the twenty-seven member states seems too complex and contingent to fit into a single model or framework. Complicating the picture still further is the fact that the range of issues that states and the EU have sought to address has itself expanded significantly throughout the lifetime of the EU-from quite localised concerns such as water pollution and habitat protection (in the 1970s) to highly complex, cross-sectoral concerns such as unsustainable consumption, climate change, and widespread biodiversity loss in the 1990s and 2000s. Nonetheless, in any given area of EU environmental policy the impact of these three interacting dynamics-Europeanisation, internationalisation, and EPI-is almost certain to be apparent.

\section{Potential coordination mechanisms}

In the late 1990s greater integration was, as noted above, the 'big idea' in EU environmental policy. However, there are good reasons to expect policy coordination to be harder to achieve at EU level than at national level. According to two experts in policy coordination:

"managing the problems of fragmentation, sectoralization and policy interdependence is not peculiar to Brussels, but the extent and nature of these problems in Brussels is of a different order from that prevailing in the Member States" (Peters and Wright, 2001, page 158).

The EU does not, for example, have a coherent 'core executive' (prime minister, cabinet, etc) in charge of the high-level policy coordination in the states. The European Commission may be the formal font of most policy initiatives, but it is relatively small.

If the EU has a 'cabinet', it is the European Council. But it meets too infrequently to get a firm grip on the detail of policy making. Political leadership [a sine qua non of effective coordination (Peters, 1998)], therefore, is fragmented across a number of different actors. In theory, there is one Council of Ministers, but in practice most of its activities are strongly divided into different sectoral formations - environment, migration, etc. Therefore, the basic institutional impediments to coordination at national level are not simply reproduced at EU level, but appear there in an even more accentuated form.

There are a whole host of mechanisms that can, in principle, be used to coordinate across policy fields. These provide the content of contemporary EU environmental governance and thus also the toolbox for developing responses to linkages between environmental change and migration. Jordan and Schout (2006) identified six main types: (i) hierarchical instruments; (ii) bureaucratic rules and standard operating procedures; (iii) staff training; (iv) specification of output or tasks; (v) horizontal instruments; and (vi) mission statements. 
Crucially, these include mechanisms that operate at the level of the core executive and those that pursue coordination at lower, interministerial levels. In the remainder of this section we examine those which have been deployed to pursue EPI.

\section{Hierarchical instruments}

According to the classical view of public administration, central management is in control of common tasks such as coordination. Following this approach, we would expect the prime minister or president to be in control, supported by his private unit or office. There might also be a special coordinating minister (or 'minister without portfolio'), whose task it is to coordinate broad clusters of policies that transcend sectoral boundaries.

The problem is that this classical view does not translate easily to the EU. There is the European Council comprising heads of state and government, but other than issue political declarations it has not played a direct role in relation to EPI. There is also no high-level committee or department in the EU overseeing the implementation of EPI. The closest example is probably the Environment Council. However, this is primarily sectoral in nature (it comprises national environment ministers) and, as such, is not really well suited to pursue EPI. There is a tradition of two or more councils meeting informally (eg, transport and environment) to tackle cross-sectoral issues, but as this normally depends on support from a particular presidency, it is not an especially robust or reliable means of coordination.

\section{Bureaucratic rules and standard operating procedures}

Building new ministries or central committees is seldom enough (OECD, 2001); adequate thought also needs to be given to how to inculcate lower-level officials with a culture of better coordination. As the $\mathrm{OECD}$ (2000, page 4) has rather nicely put it: "all too often, [administrative reforms] focus on shifting the boxes of an organization chart without enough thought to the people within those structures." 'Red tape' is often universally reviled, but procedures and rules are an extremely powerful way to institutionalise coordination. An important distinction can be made between procedures that encourage an active and/or a passive exchange of information (Jordan and Schout, 2006). In the case of passive information, the ministries that are not in the lead are entitled to receive the relevant information about spillover effects, but they have to hunt around to find out — and, should they wish to, influence-what the lead ministry is doing.

Active information, on the other hand, means that the lead department is formally obliged to ensure that other departments are informed and their views incorporated in the coordination process. Because it is a proactive way of coordination, problems are detected early on in the policy-making process, which is very much in the spirit of EPI. However, care must be taken in choosing what to share, lest it exacerbate information overload (which could, paradoxically, make coordination harder, not easier, to achieve).

In general, passive information is the norm in most OECD states and also the European Commission (Jordan and Schout, 2006, page 227). In terms of EPI, this imposes a huge administrative burden on environmental ministries, as most (if not all) sector ministries are involved in environmentally damaging activities. Other rules and procedures that support EPI can, of course, be envisaged. For example, the environment ministry could be given a formal right to veto environmentally destructive policies proposed by the sectors. Alternatively, environment ministries could be granted a right to initiate new policy-making proposals in the sectors. In practice, Jacob and Volkery (2004) could not find a single OECD state that routinely applies such rules. 


\section{Staff training}

Training (for example, on how to perform appraisals, how to consult with stakeholders, or 'green' budgets) aims to encourage officials to work in a more coordinated way. Training can raise awareness of and build commitment to a particular coordination objective. However, the contribution made by training can be quite limited when there are multiple objectives and policy procedures. Training is therefore probably best used to reinforce skills within the context of single tasks (eg, sectoral objectives), rather than tackle complex horizontal tasks. Training on how to undertake impact assessments has been especially relevant to EPI (see below).

\section{Specification of targets/tasks}

Telling each part of an organisation what contribution it should make to the achievement of a common objective (such as EPI) is a tried-and-tested coordinating mechanism. In reality, it can take many forms (ie, standardising targets or tasks) and be implemented in different ways (ie, more or less hierarchical). For example, it could include setting targets (eg, embodied in environmental regulations) or specifying tasks (eg, asking sector ministries to undertake policy appraisals or produce strategies). These can be implemented in a relatively hierarchical way (ie, the core executive determines the overall priorities, which are then passed down to the line ministries), or in a more bottom-up fashion (ie, where sectoral goals are formulated as part of a collective priority-setting process, led and supported by the centre of government). In principle, there is no one single 'best' combination.

In terms of tasks, the EU has relied more heavily on specifying tasks than outputs. Strategy-producing tasks have been especially popular with respect to EPI. These included the Cardiff Process and the Lisbon Process. Initiated in 1999, the Cardiff Process (19992004) involved different sectoral formations of the Council reporting on their environmental impacts, identifying opportunities to implement EPI and then setting targets, which would then be followed up on. It was in the spirit of the open method of coordination. Lisbon was a high-level strategy (2000-10) that aimed to make the EU the most competitive and dynamic knowledge-based economy in the world, capable of sustainable economic growth with more and better jobs and greater social cohesion. Such processes are relatively easy to set up and certainly give the political impression that 'things are being done'. However, in the EU they have tended to be done in a relatively bottom-up fashion- that is, each sector or actor produces its own coordination strategy and targets with little or no coordination with the other sectors. Tasks and targets have generally not been imposed 'top down'.

The other task-based approach is that of performing policy appraisals. This task did not take root in EU environmental policy making as early as it did at the national level (Hertin et al, 2008). In the early 2000s the Commission began to develop a single integrated impact assessment procedure (Radaelli, 2004). The 2001 Gothenburg European Council had originally called for a Sustainability Impact Assessment, but what eventually emerged from the Commission was 'impact assessment', the ' $S$ ' having been quietly ditched during internal, inter-DG negotiations. Despite some critical early reports on its performance, the new IA system has gradually taken root and the quality of individual IAs has improved quite markedly (European Court of Auditors, 2010). But whether it has actually led to greater EPI and/or sustainability is another matter. In fact, in 2004 the Commission President refocused it to give much greater attention to productivity and competitiveness issues (COM, 2004: 1377: 5). Importantly, it remains an EU-level instrument. There are, for example, no structured arrangements for involving member-state authorities in the production of IAs, even though they may possess far more information on the likely impact of proposals than Commission officials working centrally in Brussels. And even if policy appraisal in the Commission was perfectly implemented, it will never be a panacea because policy coordination in the EU is a multiactor and multilevel problem (see below). 


\section{Horizontal instruments}

These offer a more decentralised way to coordinate, in the sense that they aim to unload hierarchical coordinating structures and permit a richer and more responsive process of communication to occur between the various departments and actors. They include liaison officers (people in each department tasked with building links with their opposite numbers in cognate departments); large task forces (such as Foresight in the UK), which have a temporary status; and ongoing interdepartmental teams (with strong and weak integrators) [for details see Jordan and Schout (2006, page 47)]. A task force is a temporary committee dealing with a specific coordination problem. Voluntary participation can prevent the participating units from feeling overshadowed, but also constitutes a significant weakness - that is, key actors may decline to take part. Consequently, they may be good at signalling new coordination priorities, but weaker at ensuring these are taken up in everyday policy making (for which other instruments will be needed).

The EU-level actor that has done the most to utilise horizontal instruments has, perhaps not surprisingly, been its main administrative body-the European Commission. This has included the creation of a sustainable development and integration unit in DG for the Environment and a network of environmental correspondents spanning the various DGs. However, the integration unit has never been that well resourced or politically supported by the apex of DG for the Environment. Moreover, the coordination of EU policy is a multiactor challenge. The Commission can try all that it likes to produce better-coordinated proposals, but coordination all too easily falls apart if other actors-notably the Council and the Parliament — unpick 'coordinated' proposals later on in the policy process.

\section{Mission statements}

Mission statements seek to influence the culture in an administrative system. They may not be especially hierarchical, but they can achieve a lot, particularly in dynamic, polycentric environments such as the EU. The EU's Article 6 (which identifies EPI as a strategic goal of policy making) could be viewed as one. However, the problem with mission statements is that they often embody aspirations that are disconnected from the daily life of most policy makers. Because they often end up reflecting values that are not part of an organisation's culture, they need to be buttressed with other instruments.

To sum up, the institutional and cognitive barriers to better coordination in a complex, multilevel system such as the EU are extremely daunting. It is hardly a surprise to discover that the sectors did not willingly accept responsibility for 'greening' their own activities in the manner expected by DG for the Environment. Indeed, throughout the 2000s integration as a broad coordination objective gradually lost support. Summarising greatly, there were three main reasons for this. First, integration never received sufficient active political leadership from the EU's 'core executive'. Second, it was pursued via a relatively small number of fairly weak coordination instruments. And, third, despite widespread agreement that coordination has both a horizontal and a vertical dimension, there was an ongoing failure to conceptualise (or tackle) it in a holistic manner.

\section{The coordination of environmental and migration policy?}

In this section we explore the instruments that have been used to coordinate environment and migration policies. We reveal that only limited connections have been made between the two sets of issues; those that have, have had a strong security focus - one that tends to reflect the idea of migration as a failure to adapt and as leading to various kinds of disaster scenarios. There are no obvious hierarchical instruments that have been established solely for this purpose or specific bureaucratic rules and standard operating procedures. The topic does not appear to be high profile enough to be included in staff training sessions. And there is no 
mission statement akin to Article 6 of the Amsterdam Treaty. One country- the UK-has established the equivalent of a major research project within a central 'Office for Science' (eg, Foresight, 2011), but there appear to be no functional equivalents at EU level (other than, perhaps, the Solana-Ferrero-Waldner report - see below). Thus far (and much like EPI), the topic appears to have been coordinated via a small subset of coordinating instruments, and then mostly in a rather superficial way.

Five high-level strategic processes have been relevant:

- The Cardiff Process (1999-2004): initially, it was a partnership involving just three sectors, but was later expanded to include another six. Crucially, Justice and Home Affairs (ie, migration) was not involved, and foreign policy was included only in the third wave (ie, after 1999). At first, hopes were high that the self-imposed discipline of preparing and sharing strategies would generate new information on cross-sectoral impacts and gradually develop a sense of ownership for EPI. But, as noted above, the strategies failed to live up to DG Environment's expectations, and eventually the whole process ran out of steam. No specific links between migration and environment were identified.

- The EU sustainable development strategy (2001; revised 2006): initiated in 2001, it was fully revised and politically reinvigorated in 2006, but has always been overshadowed by the Lisbon Process (and, since mid-2010, the 'EU 2020' strategy). There are some references to migration policy, but mostly with respect to the aim of developing an intra-EU policy for the mobility of EU citizens, accompanied by policies to strengthen the integration of migrants and their families. Pledges were also made to intensify cooperation with non-EU states and work towards joint responses to control migration flows. Other than this, no specific links (or new policies) linking migration and environment were identified.

- The Lisbon Process (2000-10): at first it made only passing references to environmental protection. In 2003 DG for the Environment complained that "to many actors the environment still appears as an "add on" to the annual synthesis reports that are submitted to the European Council each spring (COM, 2003: 745, final). Nonetheless, it was always skewed heavily in the direction of economy and growth, and did not consider the migration-environment nexus.

- Impact assessment (2003-): as noted above, this was originally more sustainability focused than it is today. No one has systematically scanned all the IAs to investigate how they conceive of the environment-migration nexus. Even if many concrete links were made, the whole procedure remains an EU-level instrument. There are, for example, no structured arrangements for involving member-state authorities in the production of IAs, even though they may possess far more detailed information on the likely impact of proposals than Commission officials working centrally in Brussels (see above).

- EU policy on adaptation to climate change (2007-): EU policy in this area is now developing, but much more slowly than in relation to mitigation. In the period from 2009 to 2012 the knowledge base (eg, on impacts, on vulnerability indices) is being expanded and the Commission has undertaken to 'mainstream' existing EU policies with an adaptation dimension [eg, the white paper COM (2009) 147] to account for future impacts. Certain key sectors "where early action on adaptation is essential" were identified as developing "adaptation mainstreaming strategies" (page 8), but not, it seems, Justice and Home Affairs. After 2012, the aim is to implement these strategies. Otherwise, the Adaptation White Paper makes only passing references to the climate change-migration nexus (eg, pages 15-16). The accompanying IA, SEC (2009) 387, goes into a little more detail (eg, page 28). The potential impact of climate change on migratory flows is noted, as is the need for this to be considered in the broader EU reflection on security, development, and migration policies (pages 114, 115, and 127). 


\section{Horizontal instruments}

Two initiatives could be included under this category, both of them akin to fairly shortlived task forces. The Cecchini report (1989) sought to identify obstacles to the creation of a single market in Europe (Weale et al, 2000, page 33). The Cecchini report, or 'costs of nonEurope study', identified the nature of these barriers. Only later was an additional chapter added, which sought to assess the potential environmental impacts of an internal market. It identified some possible environmental costs (eg, increase in waste flows arising from greater economic activity, greater pollution from increasing traffic flows across borders). The possible environmental implications of wholesale migration inside the EU were not, however, directly considered. In the Solana-Ferrero-Waldner report on climate change and international security, published in 2008 and submitted to the Spring 2008 European Council, the EU's then foreign policy chief (Solana) and the European Commission (2008) warned Europe to expect "substantially increased migratory pressure" (page 4) and called for more research and early warning systems to be established. It recommended that environmentally triggered additional migratory stress should be considered in the further development of a comprehensive European migration policy, in liaison with all relevant international bodies. It generated a great deal of media comment at the time, but has not produced much political or policy follow-up. As noted, the 'Stockholm Programme' did call for a Commission Communication on links between migration, displacement, and climate change. This paper was delayed, with one reason for this being uncertainty about the evidence base. While Commission planning in the context of the GAMM has proceeded, migration policy has also been buffeted by shorter-term problems, such as the dispute between Italy and France that arose as a result of migration from North Africa in the wake of the Arab uprisings, and Denmark's plan to reintroduce passport controls at its border with Germany.

\section{Conclusions}

In this paper we have addressed three key questions. First, to what extent have linkages between migration and environmental change been evident in policy responses at EU level? Here the answer is quite straightforward. The EU has paid little if any attention to links between migration and environmental change and, when it has done so, has been prone to see these as security threats and thus as linked to simplistic environmental trigger understandings of the links. We have sought to challenge this understanding by exploring the range of factors that influence migration and the broader context within which environmental change will affect migration.

Second, it was asked whether there is evidence within EU responses that migration is viewed as a form of adaptation or as failure to adapt? The evidence suggests that the latter view tends to prevail, as EU policy has focused on the development of border controls and associated capacities. 'Migration as adaptation' requires that thought be given to the ways in which migration could build resilience in communities vulnerable to environmental change. This becomes particularly relevant when it is borne in mind that the key policy challenge may not be mass displacement as a result of environmental change, but a more complex picture of continued movement towards and not away from risk (ie, to growing urban areas, particularly in parts of Asia and Africa), as well as the issue of populations unable to move and thus at risk of being trapped in areas in which they are exposed to environmental risk. While the key motive for human migration will remain the impact of economic inequalities, it is also the case that the effects of environmental change have and will continue to interact with this economic driver. The EU is exploring scope in the context of its GAMM for forms of 'circular' or temporary migration to provide benefits for sending countries, migrants, and their families and for the countries to which they move. 
Third, we asked whether new and innovative modes of governance provide a tool kit for future action. The answer here was more positive, but largely prospective. If climate change is regarded as a potential driver of future migratory pressures, then more thought will need to be given to how the EU itself is likely to evolve in the time frames over which impacts will make their presence felt. Scenario exercises (eg, Jordan et al, 2010, chapters 10-11) can perform a useful role here. Depending on which future 'world' is selected, the prevailing policy objectives may be quite different (eg, more mitigation or more adaptation focused?). Similarly, the available stock of policy coordination instruments could also be very different. Selecting (and implementing) the best combination of instruments to fulfil these (changing and challenging political) objectives constitutes an immense political challenge for Europe in the 21 st century.

Those wishing to build stronger links between EU-level migration and environmental policy (both internal and external) can learn lessons from these experiences. More specifically, policy coordination requires a multi-instrument approach which builds on their respective strengths and weaknesses. High-level political support is a necessary but insufficient condition for success. Thought needs to be given to how the various actors in and levels of the EU can be brought together to work in a complementary manner. In relation to EPI, coordination was not really thought of as a multiactor, multilevel challenge. It tended to focus more on internal EU policies than external EU policies, where member-state control is stronger. Coordination also entails actively informing other sectors of trends and policy proposals that could disrupt their policy-making activities. In the past the natural tendency has been to shield behind policy walls and confront cross-sectoral challenges only at a late stage in the policy process (ie, the policy decision stage or, worse still, the policy implementation stage), by which time the scope for genuine, two-way coordination is greatly reduced.

Thus far, environment and migration have not been formally coordinated. In and of itself this is not necessarily a 'bad' thing - there may not have been issues that needed to be coordinated. However, it is not abundantly clear that enough coordination was ever attempted to reach a sufficiently evidence-informed judgment on the 'right' level of coordination to eventually aim for. Many of the strategic-level processes that could have explored the migration-environment nexus to see whether further coordination was merited certainly failed to do so. Reports such as that from the UK Government Office for Science (Foresight, 2011) can help to raise awareness, but other coordinating instruments will be needed to ensure that their findings are taken up in daily policy-making activities. The most obvious instruments here include the national-level and EU-level adaptation planning processes (centred on the new multiactor Adaptation Steering Group chaired by DG for Climate Action) and IA, but in order to be successful, these will need to account for the fact that policy coordination in the EU is a multilevel, multiactor challenge. Recall that more multilevel environmental governance in the EU has not yet translated into more uniform environmental governance (Weale et al, 2000, page 468). There are still basic differences in the way that governments go about governing environmental issues at national and local levels - differences that are mirrored in the way that the EU governs the relationship between environmental and migration policy.

\section{References}

Bache I, Jordan A (Eds), 2006 The Europeanization of British Politics (Palgrave Macmillan, Basingstoke, Hants)

Bakewell O, 2008, “'Keeping them in their place': the ambivalent relationship between development and migration in Africa" Third World Quarterly 29 1341-1358

Benson D R, Adelle C, 2012, "EU environmental policy after Lisbon", in Environmental Policy in the European Union 3rd edition, Eds A J Jordan, C Adelle (Routledge, London) pp 32-48

Benson D R, Jordan A J, 2008, "A grand bargain or an 'incomplete contract'? EU environmental policy after the Lisbon Treaty" European Energy and Environmental Law Report 17 280-290 
Benson D, Jordan A J, 2012, "Environmental policy”, in European Union Politics 4th edition, Eds M Cini, N Perez-Solorzano Borragan (Oxford University Press, Oxford) pp 325-337

Black R, Adger W N, Arnell N, Dercon S, Geddes A, Thomas D, 2011, "The effect of environmental change on human migration" Global Environmental Change 21 3-11

Börzel T, 2001, "Non-compliance in the European Union: pathology or statistical artefact?"Journal of European Public Policy 7 141-162

CEC, 2011a Increasing the impact of EU Development Policy: An Agenda for Change COM (2011) 637 final, Commission of the European Communities, Brussels

CEC, 2011b The Global Approach to Migration and Mobility COM (2011) 743 final, Commission of the European Communities, Brussels

European Commission, 2008, "Climate change and international security: S113/08", 13 March, Brussels

European Court of Auditors, 2010, "Impact assessments in the European institutions", Special Report No. 3, European Court of Auditors, Luxembourg

Foresight, 2011 Global Environmental Change: Challenges and Opportunities Government Office for Science, London

Geddes, A, 2005, "Europe's border relationships and international migration relations" Journal of Common Market Studies $\mathbf{4 3}$ 787-806

Geddes A, 2008 Immigration and European Integration: Beyond Fortress Europe? 2nd edition (Manchester University Press, Manchester)

Geddes A, Somerville W, 2012, "Migration and environmental change in international governance: the case of the European Union" Environment and Planning C: Government and Policy 30 $1015-1028$

Geddes A, Adger N, Arnell N, Black R, Thomas D, 2012, "Migration, environmental change and the challenges of governance" Environment and Planning C: Government and Policy 30 1078-1082

Green-Cowles M, Caporaso J, Risse T, 2002 Transforming Europe: Europeanization and Domestic Change (Cornell University Press, Ithaca, NY)

Haigh N (Ed.), 1992 Manual of Environmental Policy (Longman, London)

Hertin J, Jacob K, Volkery A, 2008, "Policy appraisal", in Innovation in Environmental Policy? Integrating the Environment for Sustainability Eds A Jordan, A Lenschow (Edward Elgar, Cheltenham, Glos) pp 24-48

Jacob K, Volkery A, 2004, "Institutions and instruments for government self-regulation" Journal of Comparative Policy Analysis 6 291-309

Jordan A J, 1999, "The implementation of EU environmental policy: a policy problem without a political solution" Environment and Planning C: Government and Policy 17 69-90

Jordan A J (Ed.), 2005 Environmental Policy in the European Union 2nd edition (Earthscan, London)

Jordan A J, Adelle C, 2012a, "EU environmental policy: contexts, actors and policy dynamics", in Environmental Policy in the European Union 3rd edition, Eds A J Jordan, C Adelle (Routledge, London) pp 1-10

Jordan A J, Adelle C (Eds), 2012b Environmental Policy in the European Union 3rd edition (Routledge, London)

Jordan A J, Adelle C, 2012c, "European Union environmental policy at 40: retrospect and prospect", in Environmental Policy in the European Union 3rd edition, Eds A J Jordan, C Adelle (Routledge, London) pp 369-386

Jordan A, Lenschow A (Eds), 2008 Innovation in Environmental Policy? (Edward Elgar, Cheltenham, Glos)

Jordan A, Liefferink D (Eds), 2004 Environmental Policy in Europe (Routledge, London)

Jordan A, Schout A, 2006 The Coordination of the European Union (Oxford University Press, Oxford)

Jordan A J, Wurzel R, Zito A, 2005, “The rise of 'new' policy instruments in comparative perspective" Political Studies 53 477-496

Jordan A, Huitema D, van Asselt H, Rayner T, Berkhout F (Eds), 2010 Climate Change Policy in the European Union (Cambridge University Press, Cambridge) 
Jordan A J, Wurzel R, Zito A R, Benson D, 2011, "Policy instruments in practice", in Oxford Handbook of Climate Change and Society Eds J S Dryzek, R B Norgaard, D Schlosberg (Oxford University Press, Oxford) pp 536-549

Jordan A J, Benson D, Wurzel R, Zito A R, 2012a, "Governing with multiple policy instruments?", in Environmental Policy in the European Union 3rd edition, Eds A J Jordan, C Adelle (Routledge, London) pp 309-325

Jordan A J, Benson D, Wurzel R, Zito A R, 2012b, "Environmental policy: governing by multiple policy instruments?", in Constructing a Policy State? Policy Dynamics in the EU

Ed. J J Richardson (Oxford University Press, Oxford) pp 104-124

Kelemen R D, 2010, "Globalising European Union environmental policy" Journal of European Public Policy 17 335-349

Lavenex S, 2006, "Shifting up and out: the foreign policy of European immigration control" West European Politics 29 329-350

Lenschow A, 2005, "Environmental policy", in Policy Making in the European Union 5th edition, Eds H Wallace, W Wallace, M Pollack (Oxford University Press, Oxford) pp 305-328

Lenschow A, 2012, "Studying EU environmental policy", in Environmental Policy in the European Union 3rd edition, Eds A J Jordan, C Adelle (Routledge, London) pp 49-72

McLeman R, Smit B, 2007, "Migration as an adaptation to climate change" Climate Change $7631-53$

Myers N, 1997, "Environmental refugees" Population and the Environment 19 167-182

Myers N, 2001, "Environmental refugees: our latest understanding" Philosophical Transactions of the Royal Society B 356 16.1-16.5

Nelson D, Adger W N, Brown K, 2007, "Adaptation to environmental change: contributions of a resilience framework" Annual Reviews of Environment and Resources 32 395-419

OECD, 2000 Government Coherence PUMA/MPM (2000) 3 (OECD, Paris)

OECD, 2001 Sustainable Development: Critical Issues (OECD, Paris)

Peters B G, 1998, "Managing horizontal government" Public Administration 76 295-311

Peters B G, Wright V, 2001, "The national coordination of European policy-making", in European Union Ed. J J Richardson (Routledge, London) pp 155-178

Radaelli C, 2002, "Whither Europeanisation: concept stretching and substantive change" European Integration On-Line Papers 4 http://eiop.or.at/eiop/texte/2000-008a.htm

Radaelli C, 2004, “The diffusion of RIA: best practice or lesson drawing?" European Journal of Political Research 43 723-747

Weale A, Prindham G, Cini M, Konstadakupolos D, Porter M, Flynn B, 2000 Environmental Governance in Europe (Oxford University Press, Oxford)

White G, 2011 Climate Change and Migration: Security and Borders in a Warming World (Oxford University Press, Oxford) 